Entrevista 



\title{
A formação inicial e continuada do professor de francês na universidade de genebra: um diálogo com a professora e pesquisadora glais sales cordeiro
}

The initial and continuing formation of french teacher in university geneve: a dialogue with the teacher and researcher glaís sales cordeiro

Cleide Inês Wittke

Universidade Federal de Pelotas, Pelotas, RS, Brasil

\begin{abstract}
Resumo: Este texto é resultado da entrevista que a professora Cleide Inês Wittke efetuou com a pesquisadora da área de didática do francês, Profa. Dra. Glaís Sales Cordeiro, durante a realização de seus estudos de Pós-Doutorado na "Faculté de Psychologie et des Sciences de l'Éducation" (FPSE). Glaís Sales Cordeiro é membro do grupo GRAFE (Groupe de recherche pour l'analyse du français enseigné), da "Université de Genève" (UNIGE), na Suíça. Esta reflexão, cujo objetivo é criar um diálogo entre a realidade genebrina e brasileira no que tange ao ensino de língua e suas implicações, principalmente no que se refere à formação inicial e também continuada do professor de língua, é produto do projeto de pesquisa intitulado: "Interface entre as teorias didática das línguas e transposição didática na formação inicial e continuada do professor de línguas", aprovado e financiado pelo governo federal, via bolsa no exterior pela Coordenação de Aperfeiçoamento de Pessoal de Ensino Superior (CAPES), em 2015.
\end{abstract}

Palavras-chave: Entrevista. Ensino de língua. Formação docente. Pesquisa.

Abstract: This text derives from an interview made by Professor Cleide Inês Wittke with Professor Glaís Sales Cordeiro, researcher in French language didactics, while doing her Post-doctorate at Faculté de Psychologie et des Sciences de l'Éducation (FPSE). Glaís Sales Cordeiro is member of the GRAFE research team (Groupe de recherche pour l'analyse du français enseigné) at Geneva University, Switzerland. This reflection, whose objective is to create a dialogue between Geneva and Brazilian realities in relation to language teachers formation, both while in their under-graduation courses and later, when already graduated, stems from a research project entitled "Interface between didactic language pedagogies and didactic transposition in under-graduation and graduation language teacher formation", sponsored by the federal government via funding provided by 
Coordenação de Aperfeiçoamento de Pessoal de Ensino Superior (CAPES), in 2015.

Keywords: Interview. Language learning. Teaching Formation. Research.

\section{Entrevistada e entrevistadora}

Glaís Sales Cordeiro é professora e pesquisadora da FPSE, da Universidade de Genebra, onde realiza seus estudos no campo da linguagem, no ensino e na aquisição da língua oral e escrita, bem como na formação de professores de francês e na supervisão de estágios. Cabe dizer

Cleide Inês

Wittke que a professora centra suas pesquisas mais especificamente na análise de elementos fundamentais ao ensino e à aprendizagem da produção e compreensão de textos orais e escritos, por meio de diferentes dispositivos de ensino. Atualmente, ela coordena, juntamente com Francia Leutenegger e Lucie Mottier Lopez ${ }^{1}$ o "Réseau Maison des Petits" com o projeto " $L$ 'enseignement et l'apprentissage de la lecture en français au cycle 1 et la régulation des apprentissages des élèves", em uma parceria entre a Direção Geral do Ensino Primário e a FPSE. Dentre sua vasta obra, destacamos sua participação no livro "La lecture enseignée au fil de l'école obrigatoire. L'exemple genevois" (et al.), publicado em 2014.

Cleide Inês Wittke é doutora em Linguística Aplicada pela PUC-RS com estágio de doutoramento-sanduíche em Transposição Didática na Universidade Paul Verlaine, em Metz-França, sob orientação do professor André Petitjean, em 2005-2006. É professora adjunta na Universidade Federal de Pelotas (UFPEL), atuando na Graduação e na Pós-Graduação do Centro de Letras e Comunicação. No ano de 2015, realizou pesquisa de pós-doutoramento sobre a Formação Inicial e Continuada do Professor de Línguas, com base na Didática das Línguas e na Transposição Didática, na Universidade de Genebra. Coordena o projeto de pesquisa "O texto/gênero textual como objeto de estudo no ensino de língua: estratégias para desenvolver a capacidade leitora e seus efeitos na expressão escrita". Seus trabalhos estão centrados em temas como ensino de línguas; formação inicial e continuada de professores; estratégias de leitura, de produção escrita e oral e de ensino de gramática; abordagem de gêneros textuais e sequências didáticas; análise de material didático.

1 Ambas são professoras da FPSE/UNIGE e membros do grupo de pesquisa GRAFE-LETC, voltado ao ensino da leitura, juntamente com a professora entrevistada. 


\section{Questionamentos e reflexões}

Cleide Wittke - Uma das maiores causas do fracasso escolar no ensino de língua na rede de ensino do Brasil está relacionada com a falta de periodicidade na prática de leitura. Até existem programas nacionais (e outros pontuais) que buscam incentivar o hábito de ler, mas, infelizmente, eles surtem pouco efeito no contexto escolar. Gostaria que você contextualizasse a realidade da Suiça, e mais especificamente de Genebra, sobre a questão do exercício da leitura, bem como apontasse sugestões que possam servir de norte ao ensino brasileiro, com vistas a incentivar o aluno a adquirir o hábito da leitura. Enfim, como pode o professor, em especial o de línguas, criar dispositivos didáticos que despertem o interesse e o prazer pela leitura? Nesse sentido, qual é, na sua opinião, o papel dos Cursos formadores de professores de línguas?

Glaís Sales Cordeiro - Vou falar principalmente do trabalho com a leitura no ensino obrigatório, o que corresponde ao ensino fundamental I e II no Brasil. Para incentivar o gosto pela leitura, acredito que os comportamentos do leitor deveriam ser mais ensinados, ou seja, encontrar respostas à questão: Como é que a gente faz para ler? E, assim, o gosto, o prazer da leitura viria desse domínio, de como é que se faz para ler. Aqui na Suíça francófona, podemos ver que a leitura está bastante presente no cotidiano das salas de aula, mas ela ainda é pouco ensinada (abordada de modo sistemático).

A partir da pesquisa sobre o ensino da leitura que a equipe GRAFE-LECT fez, coordenada pela professora Thérèse Thévenaz-Christen², é possível notar que a leitura é ensinada, principalmente nas séries iniciais, no segundo e terceiro anos. E conforme o aluno vai ficando mais autônomo na leitura, mais fluente, ela deixa de ser ensinada e começam então os questionários, com questões que na maior parte das vezes são literais, de seleção, de informações presentes no texto, porém, poucas de caráter inferencial. E nós também pudemos observar que só em algumas das aulas observadas em nossa pesquisa, há um trabalho sobre como é que se faz para ler quando, por exemplo, não se entende um texto, ou como se faz para relacionar as diferentes partes de um texto, ou ainda as imagens com o texto.

2 Thérèrese Thénevaz-Christen é professora formadora e pesquisadora da UNIGE, hoje aposentada. Ela é membro do GRAFE e organizou o livro: "La lecture au fil de l'école obligatoire. L'exemple genevois." 
Cleide Inês

Wittke

Com relação aos diferentes gêneros de texto, foi possível constatar, através dessa investigação, um trabalho eminentemente com textos da ordem do narrar. Foi observado que há poucas atividades com outros agrupamentos como os dos textos injuntivos (instrucionais), dos textos da ordem do relatar, como as notícias, e dos textos que transmitem conhecimentos, como os artigos enciclopédicos, por exemplo.

Então, existem poucos trabalhos em sala mostrando que não se lê textos de gêneros diferentes da mesma maneira. E também foi constatado que o objetivo da leitura é pouco abordado. Com isso, alguns alunos pensam que quando você quer procurar uma informação num artigo enciclopédico, por exemplo, você precisa lê-lo do início ao fim quando, na realidade, eles poderiam se basear nos subtítulos para encontrar a informação que procuram. Isso mostra que o amplo processo do ensino da leitura é pouco desenvolvido. E é justamente esse trabalho que possibilitaria mais prazer na leitura, porque o aluno se sentiria menos despreparado - já que o prazer vem, por vezes, do fato de que o aluno não tem muita dificuldade para ler. Quando ele encontra dificuldade em decodificar, em identificar as informações essenciais presentes, ou não sabe como procurar as informações no texto, certamente, ele não sentirá prazer em ler.

É por isso que o papel dos Cursos de formação do professor, a segunda parte da sua pergunta, consiste justamente em poder formar o professor para saber lidar com todas essas questões e para aprender a ensinar a ler. Os cursos de licenciaturas deveriam preparar esse futuro professor para tais problemáticas. Nesse contexto, há também a questão do material didático, que ainda é insuficiente. (Isso em termos de Brasil?) Em termos de Brasil, mas também em termos de países francófonos. Temos livros didáticos, mas, em geral, esses manuais trabalham muito com textos narrativos, como se os processos de leitura utilizados pelo leitor para ler tais textos fossem exatamente os mesmos que ele mobilizaria lendo textos de gêneros pertencentes a outros agrupamentos (modalidades). Aliás, a noção de gênero de textos está ainda pouco presente no material didático e até mesmo nas reflexões de certos pesquisadores francófonos, cujos estudos estão voltados ao ensino de leitura. Podemos dizer que ainda estamos engatinhando nesse domínio. 
Cleide Inês Wittke - Ainda que o exercício da escrita seja um saber clássico no ensino de línguas e há mais de 15 anos os Parâmetros Curriculares Nacionais $(P C N, 1998,1999)$ orientam que o ensino de língua portuguesa deve ser realizado com base na prática da leitura e da escrita, de modo geral, o meio acadêmico brasileiro, no que tange à formação de seus professores, encontra dificuldades em apontar alternativas para aperfeiçoar a qualidade desse ensino. Sabemos que há importantes grupos de pesquisa na FPSE, como é o caso dos grupos GRAFE, que se dedicam a estudar os processos de produção da escrita e seus efeitos na formação docente, no ensino de línguas. Relacionando o ensino da escrita com a modelização de gêneros textuais, você poderia fazer um relato sobre os últimos experimentos que seu grupo de pesquisa tem realizado sobre o processo de escrita?

Glaís Sales Cordeiro - O GRAFE teve uma produção muito grande sobre o ensino da escrita até o início dos anos 2000, período em que também houve uma grande produção de material didático. Nessa época, nossa equipe realizou muitas pesquisas sobre ensino de escrita a partir da noção de gênero textual e do dispositivo da sequência didática. Mas, progressivamente, o olhar dos pesquisadores foi se orientando também para outra temática, que é a do trabalho do professor, porque queríamos saber quais eram os efeitos desses materiais didáticos em sala de aula, nas práticas cotidianas dos professores. Enfim, era preciso conferir como é que o professor ensina para talvez voltar, em um segundo momento, a produzir mais materiais ou repensar os já existentes como é o caso daqueles voltados às sequências didáticas.

Posso adiantar que, desde o momento em que os textos do GRAFE foram disponibilizados no Brasil, principalmente aqueles sobre o ensino de gêneros e sequências didáticas, a equipe não produziu material novo sobre o ensino da produção escrita. Isso se deu porque, a partir daquele momento, foi dado início a pesquisas sobre o trabalho do professor com o livro "Des objets enseignés en classe de français", cuja temática voltou-se ao trabalho do professor de final de ensino fundamental e início do médio, com relação ao ensino de textos argumentativos e da oração subordinada relativa nesse contexto. 
Cleide Inês

Wittke

E também, claro, a pesquisa do Joaquim Dolz ${ }^{3}$ sobre o trabalho do professor nas instituições de formação. E depois de terminado o nosso estudo sobre os objetos ensinados em produção de textos/gramática em sala de aula, fizemos uma pesquisa acerca do trabalho com a leitura no ensino fundamental e início do médio no GRAFE-LECT, pesquisa já mencionada anteriormente. 0 resultado desse estudo foi publicado no livro "La lecture enseignée au fil de l'école obligatoire. L'exemple genevois". Depois, o GRAFE-LITT (que você conhece) começou uma pesquisa sobre ensino de literatura (hoje ainda em curso).

$\mathrm{Eu}$, de minha parte, comecei a me interessar mais pelo ensino de leitura nos anos iniciais da escolaridade, a partir do trabalho do GRAFE-LECT, com colaboração das colegas Thérèse Thévenaz-Christen e Sandrine Aeby ${ }^{4}$. No presente momento, eu sou coordenadora, juntamente com Lucie Mottier Lopez e Francia Leutenegger, do "Réseau Maison de Petits", que é uma rede de escolas, atualmente, composta por dois estabelecimentos - um estabelecimento pode conter duas ou três escolas. Na realidade, trabalhamos com três escolas e havia uma vontade muito grande dos professores em trabalhar com a leitura, mais especificamente, com a compreensão em leitura. Então, minhas pesquisas se reorientaram para a leitura e para a tentativa de ver como é que a noção de gênero de texto - que é pouco presente nos trabalhos de outros pesquisadores desse campo-, poderia ser tematizada nessas pesquisas. Com isso, a escrita aparece nos trabalhos atuais, mas como um trampolim para a leitura - em interação com a leitura - e não é o objeto principal de nossos estudos.

Cleide Inês Wittke - Como já foi dito, os PCN $(1998,1999)$ norteiam que o ensino de língua portuguesa deve ser pautado em atividades de leitura, produção oral e escrita e gramática, todavia, não aquele exercício canônico, cujo objetivo é ensinar a nomenclatura, mas por meio do uso consciente da língua, nas

3 Joaquim Dolz é professor ordinário da FPSE e coordena três pesquisas, sendo duas delas direcionadas à formação e à ação docente. Uma intitula-se "Les gestes didactiques des enseignants face aux obstacles d'apprentissage d'un genre argumentatif" e a outra "Objets et processus de la formation en didactique du français. Analyse de la formation des enseignants du primaire e du secondaire en production écrite". Ver nas referências entrevista desta autora com o professor Dolz, na ocasião de seus estudos de Pós-doutorado na Unige.

4 Sandrine Aeby é professora da FPSE e membro do GRAFE. Ela também colaborou na pesquisa realizada pelo GRAFE-LECT, dirigida por Thérèse Thevenaz-Christen. 
mais diversas situações enunciativas. Há décadas, vários autores brasileiros vêm pesquisando e refletindo sobre a mudança na abordagem do ensino de gramática, dos quais citamos Possenti (2002), Rojo (2002), Neves (2003), Travaglia (2003, 2004), Geraldi (2006), Antunes (2009), dentre outros. No entanto, poucas mudanças nos gestos didáticos podem ser percebidas na prática docente. Em contrapartida, os grupos genebrinos de pesquisa têm diversos estudos e variadas reflexões nesse campo, os quais, certamente, podem ser inspiradores às buscas dos professores brasileiros. Gostaria que explanasse sobre os resultados já obtidos e aspectos ainda sob investigação no que tange ao ensino de gramática. Nesse contexto, sob quais perspectivas teóricas e práticas os futuros professores de línguas vêm sendo formados em Genebra?

Glaís Sales Cordeiro - A distinção que se faz aqui, pelo menos na nossa equipe, é entre gramática textual e gramática da frase. Do

A formação inicial e continuada do professor de francês na universidade de genebra nosso ponto de vista, e isso o Bernard Schneuwly poderá explicar melhor na entrevista que você vai fazer com ele, há dois eixos no ensino da gramática. Para nós, e inclusive pela própria tradição do ensino de língua materna (ou primeira, com se diz aqui em Genebra), de certa maneira, na Suíça francófona existem dois grandes objetivos para a escola primária. Um primeiro objetivo é a compreensão e a produção de textos orais e escritos, e um segundo é o funcionamento da língua. No segundo enfoque, temos o ensino de gramática, ortografia, vocabulário e conjugação. Com essa abordagem, acreditamos que sim, ou seja, é necessário que haja um estudo de gramática como um domínio em si, e um estudo de gramática em uso no texto oral ou escrito. E aí existe uma grande diferença também entre gramática oral e gramática no texto escrito.

Fazendo, então, uma relação com o ensino brasileiro, eu entendo o que está acontecendo, mas meu olhar é mais crítico, pois, em um dado momento, o ensino de língua saiu de uma postura extremamente normativa com relação à gramática, pois ensinar português era ensinar gramática e ortografia (vocabulário um pouco menos) para um outro extremo. Saiu da postura normativa e foi para outra completamente oposta, que é a de ensinar sobretudo a produção de textos. Nesse sentido, a gramática só é abordada no âmbito do texto e não da frase.

E o que vejo hoje, no Brasil, pois ministro cursos de formação em algumas universidades e tenho contato também com profes- 
Cleide Inês

Wittke

186

sores do ensino fundamental e médio, é uma ausência quase total do ensino de gramática na sala de aula. Isso porque a abordagem da gramática está tão diluída no ensino de produção e no ensino de leitura que vai chegar um momento (e eu estou forçando um pouco) em que os alunos não vão conhecer mais as noções gramaticais; saber o que é um advérbio, um adjetivo, o que é uma oração coordenada ou uma oração subordinada, por exemplo. Nessas condições, podemos dizer que ainda estamos no extremo e não encontramos um equilíbrio entre esses dois grandes objetivos do ensino de língua, portuguesa, no caso do Brasil. No meu entender, e do GRAFE, esses dois eixos, produção/compreensão de textos e funcionamento da língua (gramática, ortografia, etc.), devem constituir os pilares do ensino de língua, pelos menos no ensino fundamental.

Quando se faz análise dos livros didáticos brasileiros, a gente vê que as questões gramaticais e mesmo as questões lexicais estão muito diluídas. Não se faz mais, não se objetiva mais um ensino - que também é necessário - da gramática por si mesma. Já aqui em Genebra, procuramos formar os nossos futuros professores para o ensino de produção oral e escrita, de leitura, mas também para o ensino do léxico, da ortografia e de gramática.

Assim, na formação inicial e continuada de professores, nós, formadores, mostramos como abordar esses objetos, estabelecendo relação entre atividades que você chamou de descontextualizadas, de exercícios fragmentados, e que eu entendo como uma atividade de análise da língua. Sim, muitas vezes, partimos de uma situação complexa que é o texto, via compreensão ou produção oral ou escrita, e depois propomos atividades descontextualizadas, mas que mantêm uma relação com o texto de base. Esse trabalho é feito para que as noções gramaticais sejam incorporadas e que, de fato, os alunos as estudem, porque também é função da escola trabalhar tais conhecimentos, para voltar depois, eventualmente, ao texto e poder reutilizar essas noções de modo prático. Em síntese, há um eixo da gramática em uso e outro das noções gramaticais, dos conceitos a serem apreendidos.

Por exemplo, os alunos devem ser levados a tomar consciência de como se processa a subordinação de duas frases, de como se obtém a coordenação de duas frases. Também é fundamental 
que entendam quais são os efeitos que essa coordenação ou subordinação de frases vai criar no leitor. Isso é outra questão, mas primeiro o aluno precisa entender o que são esses fenômenos para que possa empregá-los de maneira consciente na produção de um texto ou na compreensão, ao praticar a leitura, entendendo por que o autor os utilizou em seu texto. Na verdade, não se trata de primeiro ou segundo, pois não há um antes e um depois, uma vez que esses processos devem ocorrer em paralelo e precisam, ambos, serem trabalhados em sala de aula.

Em Genebra, essa questão ficou mais simples porque, até há pouco tempo, os professores chamavam de francês I (Français I) as atividades que correspondem à compreensão e produção de textos, e de francês II (Français II) as atividades que correspon-

A formação inicial e continuada do professor de francês na universidade de genebra dem a tudo que é relacionado com o estudo do funcionamento da língua. Então, os dois objetivos são bem distintos tanto para os professores quanto para os alunos, pois ambos sabem o que estão fazendo em cada um dos dois momentos, no processo de ensino e de aprendizagem de francês.

Cabe destacar que são duas disciplinas diferentes. Por exemplo, o professor pode iniciar o dia fazendo um trabalho a partir da retomada de uma produção textual já realizada e, nesse momento, trabalha sob o ponto de vista dos elementos de textualização, tais como os organizadores textuais ou a coesão verbal; depois, à tarde, ele aborda questões gramaticais: os grupos nominais e suas funções. Em síntese, são dois objetos de ensino distintos e ambos são estudados nas aulas de língua.

Quanto às referências teóricas subjacentes ao tratamento e ensino da gramática no cantão (na região) de Genebra, essas provêm da gramática distributiva e da gerativa transformacional. Nesse sentido, os processos de manipulação, substituição e supressão dos constituintes da frase são bastante importantes para o ensino e a aprendizagem da gramática de frases.

Cleide Inês Wittke- A partir dos anos 2000, iniciou-se um movimento voltado a trabalhar a língua com base nos gêneros textuais usados nas mais variadas instâncias discursivas, principalmente após a publicação do livro "Gêneros orais e escritos na escola", de Schneuwly e Dolz, que você organizou/traduziu, juntamente com Roxane Rojo, em 2004. O estudo dos gêneros textuais, via sequ- 
ências didáticas, tomou força com a campanha nacional de estímulo à produção escrita intitulada "Olimpíada de Língua Portuguesa - Escrevendo o Futuro", estendida, em 2008, também ao ensino médio, abordando um gênero para cada dois anos (ciclos). Esse movimento deu origem a muitas reflexões nesse campo teórico, mas, na prática da sala de aula, ainda restam muitas dúvidas e incertezas. Então, pergunto: como inserir de modo sistemático o ensino dos gêneros textuais e as sequências didáticas na formação dos professores de línguas? E também em cursos de formação continuada aos profissionais em serviço? De que modo esse processo ocorre na formação dos professores genebrinos e quais

Cleide Inês

Wittke são os resultados apresentados pelas pesquisas que investigam a ação docente na sala de aula sobre o ensino dos gêneros textuais?

Glaís Sales Cordeiro - Creio que resultados mais precisos da parte final desta questão possam ser dados por Joaquim Dolz (a quem você também entrevistará), uma vez que a pesquisa dele tem justamente o objetivo de investigar e refletir sobre esse tema. Então, eu não tenho muitos dados a informar, ou a acrescentar, no que tange a essa problemática.

Quanto à primeira questão, sobre como inserir de modo sistemático o ensino de gêneros e de sequências didáticas na formação dos professores de língua, penso que ela deveria constar nas ementas das disciplinas. A noção de gênero textual seria um ponto de partida e de chegada, bem definida, pois a sequência didática é apenas um dispositivo de ensino.

Se a noção de gênero textual não está bem especificada, delimitada, você pode ter sequências didáticas das mais diversas e, a meu ver, é o que acontece, às vezes, no Brasil. É verdade que há uma produção muito grande nesse domínio, pois cada vez que volto de lá, trago muitos livros (o que acho muito bom!), mas quando você analisa as sequências didáticas propostas, percebe-se que elas nem sempre se referem a gêneros textuais. Algumas podem ser sobre portadores de textos (suportes). Um exemplo disso é o ensino da sequência didática sobre o bilhete, já que um bilhete só se torna um gênero textual se você souber qual é o objetivo de sua escrita. $\mathrm{O}$ bilhete foi produzido para instruir, para relatar algum fato que aconteceu? Afinal, ele serve para quê? É assim que ele assume diferentes funções e objetivos, tornando-se um gênero preciso: um lembrete, uma nota instrucional, etc.

Nessas condições, acredito que o currículo deveria, no caso da 
disciplina de língua, começar pela explicitação do gênero textual. E então (é claro que estou partindo da visão de nossa equipe), penso que os textos escolhidos e traduzidos no livro editado em 2004 possibilitam caracterizar precisamente as dimensões constitutivas de um gênero textual. E essa caracterização terá como base os agrupamentos de gêneros que lá foram propostos, em termos das ordens do narrar, do relatar, do argumentar, etc., os quais permitem justamente entender e definir melhor cada família de gêneros.

Nessa perspectiva, há um problema fundamental na formação de base e também na formação continuada do professor: Com quais gêneros a gente pode exemplificar os diferentes agrupamentos? A dificuldade que vejo no contexto brasileiro é que

A formação inicial e continuada do professor de francês na universidade de genebra existe uma vontade muito grande de trabalhar com gêneros da atualidade ou principalmente com as novas tecnologias. Quando estive em um evento no início de 2015 no Brasil, os professores fizeram muitas perguntas sobre as novas tecnologias, e também sobre nossos trabalhos relacionados a esse tema. Os professores queriam saber, por exemplo, se uma página da web é ou não um gênero. Respondi que tudo depende daquilo que se encontra nessa página da web. É necessário que você analise cada página da web, ou cada site, pois, dependendo da página, é possível encontrar inúmeros gêneros nela.

Realmente, a questão é complexa e a escolha que fizemos aqui na equipe, com o objetivo de dar uma formação aos professores que ofereça condições de trabalhar o gênero textual na escola, foi a de estudar gêneros que têm características mais definidas (canônicas) e que apresentam poucas variações. Tomamos essa decisão porque, dessa forma, você consegue mostrar para o professor e também para os alunos quais são as dimensões que constituem e definem um gênero, ou seja, conteúdo temático, plano do texto, elementos de textualização. Com essa abordagem do gênero, fica mais fácil introduzir e depois dar continuidade a esse trabalho na progressão curricular, percorrendo todo o ensino fundamental e chegando até o ensino médio.

Esses são alguns nortes sobre o ensino de francês e também sobre a formação docente em Genebra. Na formação de base dos professores, temos duas disciplinas de didática do francês, I e II, 
Cleide Inês

Wittke

190

em dois anos diferentes da formação. No primeiro ano, preparamos os futuros professores somente para a etapa de apresentação da situação de comunicação. Os estudantes escolhem um gênero com o qual querem trabalhar e discutem com o professor titular que vai recebê-los na sala de aula, na escola. Os licenciandos fazem duas semanas do que a gente chama de "tempo de terreno" (temps de terrain), isso no segundo e no terceiro ano.

O primeiro ano de formação em Ciências da Educação é básico e somente no segundo ano os alunos são selecionados com base nos resultados dos exames, no nível de língua inglesa e alemã e de uma prova de francês, compreensão e produção de texto. Se nada mudou, acredito que continue sendo dessa forma. E então, no segundo ano, começam as disciplinas mais ligadas à formação do professor, mais voltadas à prática propriamente dita, havendo, nessa fase, o temps de terrain. Os estágios com total responsabilidade da aula ocorrem no terceiro ano da formação específica, havendo apenas um estágio curto no segundo ano.

Em Didática do Francês I, nas duas primeiras semanas, os alunos observam aulas do professor titular, observam como ele ensina a produção escrita e também fazem uma entrevista com esse profissional. Se os acadêmicos não conseguiram ver, nessas duas semanas, tudo o que o professor pode fazer em relação à produção escrita, eles podem, através de uma entrevista com este, obter mais informações. Depois, os estudantes voltam para a universidade e novamente têm aulas conosco, formadores.

Feito isso, os futuros professores retornam, após duas ou três semanas, para o trabalho no terrain e é nesse momento que eles vão fazer a apresentação da situação de comunicação aos alunos e levá-los a realizar a produção inicial dos textos do gênero escolhido. Para o trabalho de avaliação do curso, os licenciandos analisam os aspectos que funcionaram ou não nos textos produzidos pelos alunos, podendo assim tomar consciência da complexidade com a turma.

Em Didática do Francês II, no terceiro ano de formação, os futuros professores têm novamente três a quatro aulas e duas semanas de temps de terrain. Depois, mais duas semanas de aula com a gente e, novamente, duas semanas de temps de terrain. Nas primeiras duas semanas, como já fizeram no ano anterior uma 
apresentação de uma situação de comunicação e uma produção inicial, nós os preparamos menos para essa atividade. A escolha do gênero é feita juntamente com o professor titular que os recebe na escola. O quadro muda, já que não é uma continuidade do trabalho realizado no ano anterior. Na formação do docente, tudo é feito para que os estudantes trabalhem sempre em séries diferentes e com diversos titulares, com vistas a também compreender melhor a noção de progressão curricular.

Nessa fase, entramos com um novo elemento, pois é preciso levar em conta os objetivos da escola, os quais nortearão os módulos de aprendizagem a serem produzidos e aplicados nas duas últimas semanas de terrain. Nessa etapa da formação, os acadêmicos vão analisar as produções dos alunos e, a partir dos

A formação

inicial e continuada do professor de francês na universidade de genebra textos vão produzir apenas um módulo, já que, em duas semanas, não é possível programar uma atividade muito extensa. Também devem analisar essas produções do ponto de vista da ortografia e elaborar um módulo voltado ao ensino desse objeto, separado do módulo direcionado à produção escrita. Procuramos separar o ensino desses dois objetos. Todavia, isso não significa que os dois saberes não estabelecem relações, mas primeiro a gente decompõe, ou elementa/elementariza os objetos, como diz Bernard Schneuwly ${ }^{5}$ - e depois voltamos a recompô-los.

Então, a partir dessas análises que os estudantes já fizeram, eles decidem qual dimensão da produção escrita vai ser trabalhada: plano do texto ou um elemento de textualização como a conexão, como a coesão nominal, ou como a coesão verbal, ou ainda as modalizações. Tudo depende do gênero que será ensinado e das dificuldades identificadas. Já no caso do ensino da ortografia do francês, o objeto pode ser o plural do grupo nominal, ou os homófonos, ou outros elementos dessa natureza. Assim, diante dos diferentes aspectos da ortografia, o acadêmico seleciona um deles e produz um módulo com vários exercícios em progressão, trabalhando somente aquele elemento. Esses módulos sempre terminam com uma situação de produção mais controlada, uma

5 Bernard Schneuwly é professor ordinário da FPSE e coordena o grupo de pesquisa GRAFE-LITT, voltado ao ensino de francês com foco na literatura. Cabe destacar que a autora desta entrevista participou das reuniões desse grupo, uma vez que o professor Schneuwly foi supervisor de seus estudos de pósdoutorado na FPSE, no ano de 2015. 
Cleide Inês

Wittke

curta produção, não uma completa, uma produção que chamamos de simplificada. E a partir desse processo, podemos conferir o efeito do módulo nas capacidades de linguagem dos alunos. De forma resumida, é isso que temos feito na formação inicial do professor polivalente de ensino fundamental.

Já no caso da formação continuada, os professores escolhem em quais dos cursos por nós oferecidos querem participar. Eles se inscrevem e se houver número suficiente de inscritos, ministramos os cursos, os quais podem ser sobre ortografia, produção de textos, leitura, etc. No entanto, às vezes, também há projetos de escolas e somos convidados por uma instituição para dar uma formação que, nesses casos, é bem específica, pois procuramos suprir as demandas conforme as necessidades dos professores em foco. Normalmente, tomamos como base o conhecimento que eles já dominam para, a partir disso, entrar em abordagens mais específicas.

O trabalho com os gêneros não é novo e o estamos realizando desde que começamos a trabalhar com as sequências didáticas, nos anos 90. Nos últimos anos, entretanto, entraram em jogo outros parâmetros que a gente não pode sempre controlar. São os parâmetros das instruções oficiais. Várias sequências didáticas que começam com a antiga primeira série e vão até a sexta série (hoje, sétimo ano no Brasil) foram editadas nos livros didáticos "S'Exprimer en français", em 2000/2001. E esse era o material didático oficial para o ensino de produção oral e escrita em Genebra, na época. Em todas as escolas esse material foi comprado e estava sendo usado no ensino de francês. Também as provas cantonais $^{6}$, que ocorrem no final da antiga segunda série, no final da quarta e no final da sexta, eram organizadas em função de gêneros textuais, tanto para o ensino da leitura quanto da produção escrita e oral.

Porém, em 2015, quinze anos depois da publicação da coleção "S'Exprimer en Français", a Direção do ensino primário reorientou a escolha do material didático. Com a mudança, o material se-

6 Na Suíça, as regiões são denominadas por Cantão, algo similar aos diferentes estados, aqui no Brasil. Genebra pertence ao Cantão romando, cuja língua mais falada (oficial) é o francês. Já as cidades de Bern e Basel, por exemplo, pertencem a outro Cantão, onde a língua mais falada é o alemão. Nesse contexto, as provas cantonais são as avaliações oficiais realizadas em cada Cantão. 
lecionado e atualmente em uso nas escolas do cantão de Genebra mobiliza muito menos a noção de gênero. Com isso, enfrentamos um problema de formação, ou seja: Como fazer para continuar a formar nossos futuros professores na perspectiva dos gêneros textuais? Pois nós, formadores de professores, acreditamos que, para ensinar a compreensão e a produção oral e escrita, é de fundamental importância passar pela noção de gênero de texto. É assim que pensamos e, atualmente, precisamos encontrar formas de superar essa contradição e nos questionarmos: Como fazer quando os nossos livros didáticos de ensino do francês não vão na mesma direção de nossas concepções teóricas e práticas?

Cleide Inês Wittke - Infelizmente, muitas vezes, nós, formadores de profesA formação inicial e continuada do professor de francês na universidade de genebra sores brasileiros também precisamos lidar com tais incoerências referentes às nossas concepções teóricas e às diretrizes orientadas pelas instruções oficiais ou pelos livros didáticos. Como vocês estão lidando com essa realidade? Quem seleciona atualmente o material didático no ensino de francês nos cantões romandos de Genebra?

Glaís Sales Cordeiro - Não fiz análise aprofundada do material didático que há na escola pública no Brasil, mas poderia dizer que, provavelmente, no momento, há mais coerência lá do que aqui.

o que houve foi que especialistas tanto do terrain - coordenadores pedagógicos, pessoas que trabalham nesses grupos mais ligados às Direções de ensino dos cantões francófonos e também pesquisadores - fizeram uma avaliação de vários livros didáti$\cos$, todos franceses, os quais não tomam o gênero textual como base, uma vez que as sequências didáticas foram produzidas por pessoas daqui, de Genebra ou da Suíça francófona. A editora de "S'Exprimer en Français" é belga, mas foi a comissão romanda de material de ensino (COROME) que também o financiou. Enfim, é uma direção dupla entre essa comissão e a editora belga.

No entanto, os livros didáticos comprados a partir de 2010 são produzidos e publicados por editoras francesas. São livros concebidos para a escola francesa. A noção de gênero textual está muito pouco presente nas pesquisas francesas e ainda menos nas escolas da França. Resumindo, isso não quer dizer que a noção de gênero não apareça nesse material didático. Fala-se de gêneros, mas os princípios para definir um gênero são totalmente distin- 
tos dos da nossa equipe e, por vezes, é mais uma confrontação com a variedade de gêneros que é proposta do que propriamente um trabalho sistemático com gêneros. E me parece que essa abordagem é bastante semelhante ao método empregado em alguns livros didáticos que circulam no ensino brasileiro.

Cleide Inês Wittke - Embora existam autores pesquisando sobre o processo de ensino da produção oral, o trabalho com esse saber ainda é bastante recente na rede escolar brasileira e também é pouco desenvolvido na formação do pro-

Cleide Inês

Wittke

194 fessor de língua materna (primeira). Gostaria de saber se o ensino da produção oral é tratado com a mesma importância dada ao ensino da leitura, da escrita e da gramática? E como esse saber é construído na formação do professor de língua francesa?

Glaís Sales Cordeiro - A produção oral aparece com a mesma importância nos parâmetros curriculares da Suíça francófona. É preciso dizer que, até 2010, tínhamos parâmetros curriculares específicos para o ensino de Genebra. E nesses parâmetros curriculares, a noção de gênero era fortemente apresentada com exemplos de gêneros orais, para compreensão em leitura e para a produção escrita, e isso para cada ação de linguagem (narrar, relatar, argumentar, etc.). Em síntese, esse ensino era realmente bem detalhado e sistematizado.

Com os parâmetros em vigor atualmente, realidade já explicada na resposta dada à questão anterior, continua-se a ter produção escrita, produção oral, compreensão escrita e oral, e também referências à noção de gênero, todavia, de modo mais superficial. 0 problema é que nos livros didáticos propostos para o professor - principalmente nos livros adotados nas séries iniciais (antigas primeira e segunda séries), a tônica é a construção do sistema alfabético, com base na aprendizagem das correspondências fonema-grafema e de outros aspectos da ortografia. E, além disso, o professor deve trabalhar com a produção escrita, com a compreensão, e ainda com a produção oral. E o que vai ficar como parente pobre? Certamente, a produção oral.

Nas provas cantonais anteriores à adoção desses novos livros didáticos, e anteriores ao novo plano de estudos romando (os parâmetros curriculares atuais na Suíça francófona), havia uma parte reservada à prática da compreensão e da produção oral. No 
entanto, atualmente, ainda que o ensino da produção oral apareça nas instruções oficiais, na prática cotidiana da sala de aula, ele é pouco realizado. Essa atividade acaba sendo minimizada, ou seja, se der tempo, trabalha-se com a compreensão e a produção oral.

No que diz respeito à questão de como esse saber é construído na formação do professor, posso dizer que temos cursos voltados especificamente ao ensino do oral, como faz o professor Joaquim Dolz. Eu também tenho um curso sobre o ensino do oral, voltado à escola maternal, mas, infelizmente, faz alguns anos que não o ministro. Isso acabou acontecendo porque ofereci um novo curso sobre a aprendizagem da compreensão em leitura, na escola maternal, e não foi possível dar conta dos dois ao mesmo tempo.

Minha intenção inicial era oferecer um em um ano e o outro A formação inicial e continuada do professor de francês na universidade de genebra no ano seguinte. Assim, a cada ano, pelo menos uma turma teria uma formação específica sobre o ensino do oral ou da compreensão em leitura no início da escolaridade. Mas, infelizmente, ainda não foi possível colocar esse projeto em prática. Cabe destacar que não se trata somente de um trabalho com o oral dialógico, mas o objetivo é trabalhar com os gêneros de textos orais.

A UNIGE forma tanto professores que atuam no ensino fundamental quanto no médio, pois se trata de uma configuração diferente da formação de Letras no Brasil. A seção de Ciências da Educação, que pertence à Faculdade de Psicologia e Ciências da Educação, propõe os três primeiros anos da formação dos futuros professores do ensino fundamental, cuja formação é de professor polivalente (generalista). Já o último ano dessa formação é assumido pelo Instituto Universitário de Formação dos Professores (IUFE). Inclusive, recentemente foi construído um prédio para esse Instituto, aqui na Universidade de Genebra. O IUFE também forma os professores do ensino médio.

Vale destacar que as modalidades de entrada nessa formação são diferentes do acesso às licenciaturas nas universidades brasileiras. Os estudantes que entram no curso de formação para o ensino fundamental, acabaram de terminar o ensino médio. Esses alunos possuem um certificado de fim do ensino médio, porque não temos o vestibular ou Enem, aqui. É com esse certificado que os estudantes entram na Universidade. É necessária uma formação completa de quatro anos para se tornar professor do ensino 
Cleide Inês

Wittke

196

fundamental. Essa formação poderia equivaler um pouco à Pedagogia, no Brasil, mas não é exatamente a mesma formação, porque aqui, além das disciplinas voltadas para os aspectos transversais do ensino e da aprendizagem, os estudantes se formam também em todas as didáticas disciplinares: do francês, da matemática, das ciências, de estudos sociais, etc. $\mathrm{E}$ também em didática comparada.

No que tange à formação dos professores que atuarão no ensino médio, para estarem aptos a ensinar o francês, eles devem ter uma licença em Letras. Isso significa que já fizeram os quatro anos de Letras e vão fazer mais três anos de formação específica para ensinar. Nesse caso, é uma formação em didática (mas também pedagógica sobre o ensino e a aprendizagem de modo geral), em didática do francês e de mais uma disciplina, de História, por exemplo. Trata-se de um público diferente, pois esses estudantes já possuem uma licença. $O$ diploma que tanto os professores do ensino fundamental quanto os do médio vão ter em mãos é um diploma dado pelo Instituto Universitário de Formação de Professores (IUFE).

Cleide Inês Wittke - Buscamos, hoje, no Brasil, formar um professor mediador, aquele que seleciona o objeto de ensino e, em conformidade com a estrutura sequencial e hierárquica das sequências de ensino, procura construir em parceria com o aluno o objeto ensinado, via aprendizagem. De forma resumida, se é que isso é possível, você poderia traçar um perfil ideal do professor de línguas na perspectiva teórica da Didática das Línguas? As pesquisas voltadas ao processo de organização do trabalho do professor em sala de aula mostram a existência desse profissional atuando nas escolas de Genebra?

Glaís Sales Cordeiro - Esta é uma pergunta difícil de responder. Primeiro, eu diria um perfil ideal no enfoque teórico da Didática das Línguas, tal qual é pensado pelo GRAFE, porque você não pode generalizar, pois existem muitas outras perspectivas. Então, para nós, o professor de línguas deve ser um professor mediador. Mas mediador de quê? Para nós, o famoso triângulo didático ${ }^{7}$ é um ponto de partida para responder a essa pergunta, pois, com base nele se tem, acima de tudo, a preocupação com o objeto de ensino e como ele é ensinado em sala de aula.

7 Trata-se do triângulo didático desenvolvido pela teoria da transposição didática de Chevellard (1985), definido por três polos: professor, aluno e saber. 
A mediação do professor, para nós, passa pelo objeto a ser ensinado e é nesse ponto que construímos todo esse enraizamento em Vygostki (2008) e trazemos a metáfora da transformação da natureza, com base em Marx (1867), para assim chegar à questão das ferramentas ou instrumentos usados pelo professor. De forma muito resumida, como você disse, para mim, o professor ideal é aquele que consegue identificar com precisão um objeto de ensino e pensa sua mediação através desse objeto.

Esta é a primeira parte da resposta. Quanto à questão do saber se as pesquisas voltadas ao trabalho dos professores em sala de aula mostram a existência desse profissional atuando nas escolas de Genebra, posso dizer que os resultados do nosso livro "Des objets enseignés" ${ }^{8}$, com relação ao ensino médio, mostram

A formação

inicial e continuada do professor de francês na universidade de genebra tal tendência, mas essa é uma questão muito complexa e difícil de ser detalhada e exemplificada.

Nesse livro, a expectativa que se tinha - a partir desse exemplo é possível modular melhor a sua questão - é que os professores partem de uma abordagem comunicativa de ensino dos objetos e não de uma perspectiva representacional da língua como tradução do pensamento. Nossos resultados situam o trabalho do professor em ambas as abordagens, num percentual de $50 \%$ para cada uma. Com esse resultado pôde-se conferir, por exemplo, qual foi o impacto da formação continuada de professores para o trabalho com gêneros textuais através de sequências didáticas, pois também existem sequências didáticas na coleção “S'Exprimer en Français" voltadas para o ensino médio.

Observamos, então, que $50 \%$ dos professores se inspiram em uma abordagem comunicativa, que pode passar pelos gêneros de texto. Isso porque, dentro desses $50 \%$, poucos são os que apresentam uma abordagem sistemática organizada a partir do gênero textual escolhido para o trabalho. A gente vê que, de vez em quando, emergem, nesse trabalho, traços de uma abordagem representacional. Isso mostra o que chamamos de "as camadas sedimentadas" de diferentes perspectivas de ensino. Com relação ao objeto "produção de textos argumentativos" (tema da pesqui-

8 A professora Glaís Sales Cordeiro refere-se à obra "Des objets enseignés en classe de français. Le travail de l'enseignant sur la rédaction de textes argumentatifs et sur la subordonnée relative", produzida e publicada em 2009 pelo grupo GRAFE, sob organização dos professores Bernard Schneuwly e Joaquim Dolz. 
Cleide Inês

Wittke

sa), os outros $50 \%$ situam-se na perspectiva representacional de tradução do pensamento, tendo como referência o tradicional ensino da dissertação e não a produção de um gênero de texto dentro de uma dada situação de comunicação.

Fica mais fácil responder sua pergunta a partir desses resultados, mas com relação ao papel do professor mediador, é difícil saber se os professores que assumiram uma abordagem comunicativa em seu ensino construíram, de fato, suas mediações com base no objeto ensinado. Uma boa resposta a essa questão exigiria que os dados coletados fossem revisitados para então conferir se, no caso desses professores, as mediações passam ou não pelo objeto de ensino.

Cleide Inês Wittke - Em vários estudos do grupo GRAFE, como é o caso do artigo "Les constructions de l'objet enseigné et les organisateurs du travail ensignant", de Cordeiro e Schneuwly (2007), fala-se em memória didática. Então, pergunto, em que consiste essa memória didática? Qual sua relação com o objeto de ensino, ou melhor, com o processo de ensino e de aprendizagem?

Glaís Sales Cordeiro - Justamente, a memória didática foi um dos aspectos que nós não pudemos desenvolver nesta pesquisa do GRAFE sobre o trabalho do professor. No nosso estudo, mostramos que a construção da memória didática está diretamente relacionada com os gestos didáticos fundamentais do ensino.

$\mathrm{O}$ primeiro gesto consiste em colocar em prática um dispositivo didático, o qual depende das instruções que são dadas, das reformulações de instruções que o professor pode dar, na medida em que vai apresentando e realizando a tarefa. Em seguida, há o que chamamos de regulações, os diversos tipos de regulações internas ou locais, que permitem ajustar o processo de ensino e de aprendizagem. Além disso, existem as institucionalizações, momentos de "fixação do saber", cuja análise foi desenvolvida por Sandrine Aeby, professora responsável pelo tema na pesquisa, e, por fim, vem a construção da memória didática.

Infelizmente, o pesquisador que era responsável por esse último gesto, pois temos o costume de dividir o trabalho na organização de nossas pesquisas, acabou não podendo continuar a trabalhar com o grupo. Nessas condições, nosso estudo ficou somente no nível da definição da construção da memória didáti- 
ca. Para nós, é tudo aquilo que antecipa o que vai ser feito ou se relaciona com o saber que já foi trabalhado em aula.

Pudemos observar que em todo o processo de ensino existe uma memória do que já foi feito e do que ainda será realizado. Por exemplo, quando o professor diz: "Nós estamos trabalhando hoje com os organizadores textuais, porque no texto que vamos escrever no final da sequência de atividades, vocês serão levados a usar esses organizadores textuais para articular as diferentes partes do referido texto". Ou ainda, quando diz: "Vocês se lembram que tínhamos trabalhado com as subordinadas relativas no ano passado? Hoje vamos utilizá-las no texto que vamos escrever". Esses são exemplos de dizeres que remetem à memória didática e ajudam a construí-la.

A formação

inicial e continuada do professor de francês na universidade de genebra

Cleide Inês Wittke - No Brasil, boa parte dos professores da rede do ensino básico organiza e ministra suas aulas a partir de um livro didático, trazendo esporadicamente atividades extras. No ensino de francês em Genebra, o livro é utilizado? Os futuros professores de francês recebem formação para construir um material didático apropriado a cada ciclo? o que você pensa sobre o uso do livro no ensino de línguas?

Glaís Sales Cordeiro - Ao longo de minhas respostas, já apresentei alguns elementos que respondem parcialmente essa pergunta. Sim, na maior parte das ocasiões aqui, no ensino de francês, parte-se de um livro didático. É o livro de base, e os futuros professores de francês recebem formação, sobretudo, para saber usá-lo e menos para construir o material didático. Temos dois veios nessa questão, vamos dizer assim.

Quando novos livros didáticos são adotados na escola pública, como o material que está em vigor no momento, o departamento de ensino propõe cursos de formação aos professores para o uso 
Cleide Inês

Wittke

200

desses livros didáticos. Às vezes, os próprios autores são convidados para apresentar o material. Na verdade, é um trabalho de apresentação da obra, das unidades que a constituem, e também esclarece como ele foi pensado.

Nós, professores da Universidade, procuramos fazer uma análise do material didático com nossos alunos, futuros professores. Para nós, o professor não é um mero aplicador. E não nos cansamos de repetir aos alunos que não estamos aqui para ensinar a eles como navegar ao longo do livro didático. Nosso trabalho consiste, sim, em ensinar como usar de modo crítico o material adotado. Então, usar um livro didático é saber fazer escolhas em função de objetivos de aprendizagem, é saber analisar justamente os exercícios, as atividades e tomar decisões com relação ao planejamento de suas aulas, à progressão curricular, tendo como ponto de partida e de chegada tais objetivos.

Nesse sentido, acredito ser o livro um instrumento interessante ao ensino, mas seu uso deve ser crítico e precisa funcionar como suporte para planejar e realizar a aula. Nós já defendemos muitas vezes esse ponto de vista no Brasil, o Bernard Schneuwly, Joaquim Dolz e eu, pois entendemos que a função do professor não é a de criar material didático, mas a de ensinar, de dar aulas. A profissão do professor consiste em saber apreciar e utilizar o material didático para alcançar os fins que pretende atingir com base nas orientações das instruções oficiais, dando conta do programa, ou melhor, do currículo.

Portanto, o professor deve se questionar quanto ao uso do livro didático que tem à disposição: "Como faço para atingir minhas metas de ensino?" E o professor pode e deve, é claro, também criar atividades e exercícios, porque ele tem, de certa maneira, um leque de possibilidades e, para nós, professores formadores, não é papel do professor criar absolutamente tudo. Nesse ponto temos algumas diferenças com relação a alguns pesquisadores brasileiros que vêm trabalhando na produção de material didático com o professor, principalmente durante sua formação, na graduação.

Nós acreditamos que não é o papel do professor criar material. Para criar um material didático você tem muitas variáveis para controlar relacionadas à transposição didática do objeto a 
ser ensinado. Para isso, os autores de livros didáticos se apoiam em conhecimentos provenientes de outras esferas do saber para transpô-los e modalizá-los no âmbito da esfera escolar, em função dos objetivos de ensino de cada ciclo de aprendizagem, de cada série. É um trabalho complexo que leva em conta, tanto esses objetivos como as capacidades reais e potenciais dos alunos a quem se destina tal material. Então, como o professor vai dar conta de ensinar e ao mesmo tempo preparar o material didático, levando em consideração todas as variáveis existentes? Parece-me muito difícil.

Eu digo isso por experiência própria, pois tive a oportunidade de criar uma sequência didática sobre compreensão em leitura para a escola maternal. Com essa produção, pude sentir como

A formação inicial e continuada do professor de francês na universidade de genebra

Cleide Inês Wittke - Não poderia finalizar nosso diálogo sem falar sobre um tema bastante complexo e polêmico: o processo de avaliação. Ao ler o artigo "Gêneros na escola: forma escolar e ensino-aprendizagem de língua", de Schneuwly e Cordeiro (2010), notei que vocês falam em regulações internas e regulações pontuais (locais) nas sequências de ensino, conforme já mencionado na resposta da questão oito. Se bem entendi, essas regulações são estratégias avaliativas, principalmente para reforçar ou mesmo reformular as atividades propostas, quando o professor percebe que seu aluno apresenta dificuldades na aprendizagem. Como funcionam esses dispositivos reguladores e qual sua relação com a avaliação formal do sistema escolar?

Glaís Sales Cordeiro - Nós não aprofundamos muito a questão da avaliação formal em nossas pesquisas. Na seção de Ciências da Educação aqui na FPSE, temos uma equipe dirigida pela pro- 
Cleide Inês

Wittke

fessora Lucie Mottier Lopez ${ }^{9}$, que é especialista em sistema de avaliação. Na nossa equipe, nós desenvolvemos mais a questão da regulação como gesto didático e também a função das grades de avaliação nas sequências didáticas.

Temos uma definição das regulações que não é necessariamente a definição que você vai encontrar, às vezes até com os mesmos termos, em outras pesquisas. Por exemplo, o que chamamos de regulação interna diz respeito a formas de regulação instrumentada, como as grades de avaliação que permitem que o aluno organize, planeje o texto em função das características do gênero em estudo. Elas o auxiliam no modo como vai organizar o texto, principalmente levando em conta os aspectos que estão listados na grade, os quais são elementos referentes ao plano de texto, aos conteúdos temáticos, etc. Mas as outras ferramentas como um contra-exemplo ou um texto modelo também constituem formas de regulação interna. Em síntese, são instrumentos que possibilitam uma autorregulação da parte do aluno.

Já as regulações que chamamos locais, ou pontuais, como você traduziu, são aquelas regulações que acontecem durante a construção do objeto, nas interações do professor com os alunos. Ela se processa quando os alunos levantam a mão, fazem uma pergunta, ou quando o professor observa que tem um aspecto que vale a pena ser mais desenvolvido, mais detalhado, e ele se afasta um pouco do plano de sua aula para desenvolver mais essa questão. Ou ainda, quando há obstáculos na aprendizagem dos alunos e o professor precisa retomar o conteúdo em estudo, insistindo ou desenvolvendo mais esse conteúdo.

$\mathrm{Na}$ realidade, vejo esses instrumentos de regulação, e esses gestos didáticos fundamentais, como algo que participa da construção do objeto ensinado, e, a meu ver, tem pouca relação com a questão da avaliação formal. Sob esse ponto de vista, nossa equipe aborda pouco sobre a questão. Em nossos trabalhos, enfocamos a avaliação das capacidades dos alunos através de gra-

\footnotetext{
9 Lucie Mottier Lopez é professora associada na FPSE e responsável pela equipe de pesquisa em Avaliação, regulação e diferenciação das aprendizagens nos sistemas de ensino (EReD). Ela também é corresponsável pelo "Réseau Maison des Petits", juntamente com Glaís Sales Cordeiro e Francia Leutenegger sob o projeto "Enseignement de la lecture au cycle élémentaire et régulation des apprentissages des élèves" (RMDP, 2014-2018).
} 
des que podem ser utilizada nos momentos de apropriação das características dos gêneros pelos alunos, durante uma sequência didática. São grades que também podem ser usadas no final da sequência quando o professor vai dar uma nota, vai avaliar a progressão do aluno do início ao final da sequência. É, assim, uma avaliação relativa aos aspectos do texto que foram contemplados, aos níveis de funcionamento linguístico que foram trabalhados e dominados ou não pelo aluno. Mas paramos nesse ponto, não indo mais adiante em reflexões sobre a avaliação formal propriamente dita e suas diferenças com relação à avaliação formativa, por exemplo.

É todo o processo de construção do objeto de ensino que nos interessa, tanto do ponto de vista do aluno, quanto do papel me-

A formação inicial e continuada do professor de francês na universidade de genebra

\section{REFERÊNCIAS}

ANTUNES, Irandé. Língua, texto e ensino: outra escola possível. São Paulo: Parábola, 2009.

CHEVALLARD, Yves. La transposition didactique. Du savoir savant au savoir enseigné. Grenoble: La pensée sauvage, 1985.

CORDEIRO, Glaís Sales e SCHNEUWLY, Bernard. Les constructions de l'objet enseigné et les organisateurs du travail enseignant. Recherche et Formation, no 96, 2007, p. 67-79.

DOLZ, Joaquim; NOVERRAZ, Michèle; SCHNEUWLY, Bernard. $S$ 'exprimer en français. Séquences didactiques pour l'oral et pour l'écrit. Notes méthodologiques. Volume I, II et III. Bruxelles: De Boeck \& Larcier. COROME, 2001. 
GERALDI, João Wanderley. o texto na sala de aula (Org.). São Paulo: Ática, 2006.

MARX, Kal. o Capital. Editora Friedrich Engels, 1867.

MEC/SEF Parâmetros Curriculares Nacionais (PCNs) - $3^{\circ}$ e $4^{\circ}$ ciclos do ensino fundamental: Língua Portuguesa. Ministério da Educação e de Desportos Secretaria de Educação Fundamental, Brasília, 1998.

Cleide Inês Wittke

204 Parâmetros Curriculares Nacionais do Ensino Médio Linguagens, códigos e suas tecnologias. Brasília: Ministério da Educação, 1999.

NEVES, Maria Helena Moura. Que gramática ensinar na escola? São Paulo: Contexto, 2003.

OLIMPÍADA DE LÍNGUA PORTUGUESA - Escrevendo o Futuro Cenpec: cenpec.or.br/olimpiada de lingua portuguesa - disponível em: $w w w$. escrevendoofuturo.org/br acesso em fevereiro de 2012.

POSSENTI, Sirio. Por que (não) ensinar gramática na escola. Campinas: Mercado de Letras, 2002.

ROJO, Roxane (Org.). A prática de linguagem na sala de aula. Praticando os PCNs. São Paulo: Mercado Aberto, 2002.

SCNHNEUWLY, Bernard; CORDEIRO, Glaís Sales. Gêneros na escola: forma escolar ensino-aprendizagem de lingual. In: 30 olhares para o futuro. São Paulo: Escola da Vila-Centro de Formação, 2010, p. 91-97.

SCHNEUWLY, Bernard e DOLZ, Joaquim. Des objets enseignés en classe de français. Le travail de l'enseignant sur la rédaction de textes argumentatifs et sur la subordonnée relative. Rennes: Presses Universitaires de Rennes, 2009.

Gêneros orais e escritos na escola. São Paulo: Mercado de Letras, 2004. 
THÉVENAZ-CHRISTEN, Thérèse. (Org.) La lecture enseignée au fil de l'école obrigatoire. L'exemple genevois. Namur: Presses Universitaires de Namur, 2014.

TRAVAGLIA, Luiz Carlos. Gramática e interação: uma proposta para o ensino de gramática. São Paulo: Cortez, 2003.

A formação inicial e continuada - Tipologia textual, ensino de gramática e o livro didático. In: do professor HENRIQUES, C. \& SIMÕES, D. (Orgs.). Língua e cidadania: novas persde francês na pectivas para o ensino. Rio de Janeiro: Ed. Europa, 2004. universidade de genebra

VYGOSTKI, Lev Semenovitch. Pensamento e linguagem. São Paulo:

WITTKE, Cleide Inês; DOLZ, Joaquim. Ensino de língua, formação docente e pesquisa: um diálogo com Joaquim Dolz. Fórum Linguístico, Florianópolis, v.12, n.4, out./dez.2015, p.986-997. 
